\title{
THE FINANCIAL CRISIS AND PORTFOLIO DIVERSIFICATION TO EUROPE
}

\author{
Grady Perdue, University of Houston-Clear Lake \\ Michael E. Hanna, University of Houston-Clear Lake \\ Joseph P. McCormack, University of Houston-Clear Lake
}

dx.doi.org/10.18374/EJBR-13-3.10

\begin{abstract}
This research examined the implications of international diversification during the recent worldwide financial crisis, which was a period of extreme volatility in the financial markets. We analyzed both a $100 \%$ US portfolio and a set of diversified portfolios that each had a major European component. Results of the analysis showed that on a risk-adjusted basis during this time period, the internationally diversified portfolios all underperformed the $100 \%$ US portfolio, raising the question of the value of international diversification at the very moment its risk-reduction quality is needed.
\end{abstract}

Keywords: International, Investing, Diversification, Sharpe Ratio. 